\title{
Benefit-cost ratio of projects: its most general form and a new graphical method for its evaluation
}

S. KHALID ASMI

\section{Mr R. B. W. Bannerman}

The method of evaluation by graphical means outlined in the Paper is so simple that it should be brought to the attention to all engineers working in this field.

19. Some will no doubt be deterred by the necessity of drawing a family of 14 (the number used by the Author) or more curves, each of which will require the calculation of several points to secure the necessary accuracy in drafting. This preliminary work can be greatly reduced by the use of semi-log paper, which reduces the curves to a series of parallel straight lines.

20. To illustrate this point, approximate annual values (to the nearest integer) have been given to the Author's cost and benefit curves in Table 1 and these are shown on Fig. 11. For the sake of brevity, only the simplest case, that of constant interest at $6 \%$ per annum has been calculated. Varying rates of interest could, of course, be shown by altering the slope of the growth curves. To arrive at present values it is not necessary to count the squares, the value of the nearest growth line on the lefthand ordinate can be read off; the value 5.75 in the year 2000 has a value of unity at the beginning of 1970 .

Mr C. J. Littleworth, Department of Water Affairs, South Africa

The Author is to be congratulated on a simple, and most readily understandable presentation of what is, in reality, a most complicated business. I have been involved from time to time in the calculation of water tariffs.

22. Although, on the face of it, the two problems sound as though they have nothing in common, they are in fact similar. The Author's problem is the proportioning of future cash flows inward and outward, and my problem is the equating thereof.

23. Suppose a certain work has a life of 5 years during which annual expenditures and consumptions are as given below

$\begin{array}{ll}\text { Year } & 122345 \\ \text { Expenditure (money units) } & a b c d e \\ \text { Consumption (volume units) } & A B C D E\end{array}$

Suppose a tariff $x$ has to be calculated so that, at a rate of interest $i$, income will balance expenditure and interest at the end of the life of the structure.

24. At the end of the first year the position is

$\begin{array}{lc}\text { Expenditure } & a \\ \text { Income } & A x \\ \text { Balance } & \frac{A x}{a-A x}\end{array}$

Paper published: Proc. Instn Civ. Engrs, 1971, 50, Oct., 161-168. 
25. During the second year, the situation is

\begin{tabular}{|c|c|}
\hline $\begin{array}{l}\text { Interest } \\
\text { Expenditure }\end{array}$ & $\begin{array}{c}(a-A x) i \\
b\end{array}$ \\
\hline $\begin{array}{l}\text { Subtotal } \\
\text { Income }\end{array}$ & $\begin{array}{c}(a-A x)(1+i)+b \\
B x\end{array}$ \\
\hline Balance & $(a-A x)(1+i)+(b-B x)$ \\
\hline
\end{tabular}

The calculation is so straightforward that it is unnecessary to follow every step. Sufficient to say that the balance at the end of the fifth year is

$$
(a-A x)(1+i)^{4}+\left(b-\frac{B x}{1}\right)(1+i)^{3}+\left(c-\frac{C x}{0}\right)(1+i)^{2}+(d-D x)^{(1+i)}+(e-E x)^{(1+i)}
$$

Table 1

\begin{tabular}{|c|c|c|c|c|}
\hline \multirow{2}{*}{ Year } & \multicolumn{2}{|c|}{ Cost } & \multicolumn{2}{|c|}{ Benefit } \\
\hline & Actual & $\begin{array}{l}\text { Discounted } \\
\text { at } 6 \% \text { p.a. }\end{array}$ & Actual & $\begin{array}{l}\text { Discounted } \\
\text { at } 6 \% \text { p.a. }\end{array}$ \\
\hline $\begin{array}{l}1970 \\
1971 \\
1972 \\
1973 \\
1974 \\
1975 \\
1976 \\
1977 \\
1978 \\
1979 \\
1980 \\
1981 \\
1982 \\
1983 \\
1984 \\
1985 \\
1986 \\
1987 \\
1988 \\
1989 \\
1990 \\
1991 \\
1992 \\
1993 \\
1994 \\
1995 \\
1996 \\
1997 \\
1998 \\
1999\end{array}$ & $\begin{array}{r}12 \\
13 \\
14 \\
15 \\
16 \\
17 \\
18 \\
15 \\
12 \\
9 \\
6 \\
6 \\
6 \\
6 \\
6 \\
6 \\
6 \\
6 \\
6 \\
6 \\
12 \\
12 \\
8 \\
8 \\
8 \\
8 \\
8 \\
8 \\
8 \\
8\end{array}$ & $\begin{array}{r}12 \\
12 \\
12 \\
13 \\
13 \\
13 \\
13 \\
10 \\
8 \\
5 \\
3 \\
3 \\
3 \\
3 \\
3 \\
3 \\
2 \\
2 \\
2 \\
2 \\
4 \\
4 \\
2 \\
2 \\
2 \\
2 \\
2 \\
2 \\
2 \\
2\end{array}$ & $\begin{array}{r}- \\
- \\
- \\
6 \\
6 \\
8 \\
10 \\
12 \\
14 \\
16 \\
18 \\
20 \\
22 \\
24 \\
26 \\
28 \\
30 \\
30 \\
27 \\
24 \\
21 \\
18 \\
15 \\
12 \\
9 \\
7 \\
5 \\
3 \\
3\end{array}$ & $\begin{array}{r}- \\
- \\
- \\
5 \\
4 \\
6 \\
7 \\
8 \\
9 \\
10 \\
10 \\
11 \\
11 \\
11 \\
11 \\
11 \\
11 \\
11 \\
9 \\
7 \\
6 \\
5 \\
4 \\
3 \\
2 \\
2 \\
1 \\
1 \\
1\end{array}$ \\
\hline Total 30 years & 289 & 161 & 414 & 175 \\
\hline
\end{tabular}


26. The inference is obvious. In the general case, if the balance at the end of $n$ years is to be zero, then

$$
x=\frac{\sum_{1}^{n} A_{n}(1+i)^{n-1}}{\sum_{1}^{n} A_{n}(1+i)^{n-1}}
$$

where $n$ is counted backwards from the end of the period. That is to say, annual expenditures and annual consumption figures are both discounted forward to the end of the equalizing period. Dividing total discounted expenditure by total discounted consumption gives the tariff in rupees per cubic metre or whatever other units may be employed.

27. Applying the same reasoning to the Author's problem, I would like to suggest two things. First, if the Author turns his discounting graph paper the other way

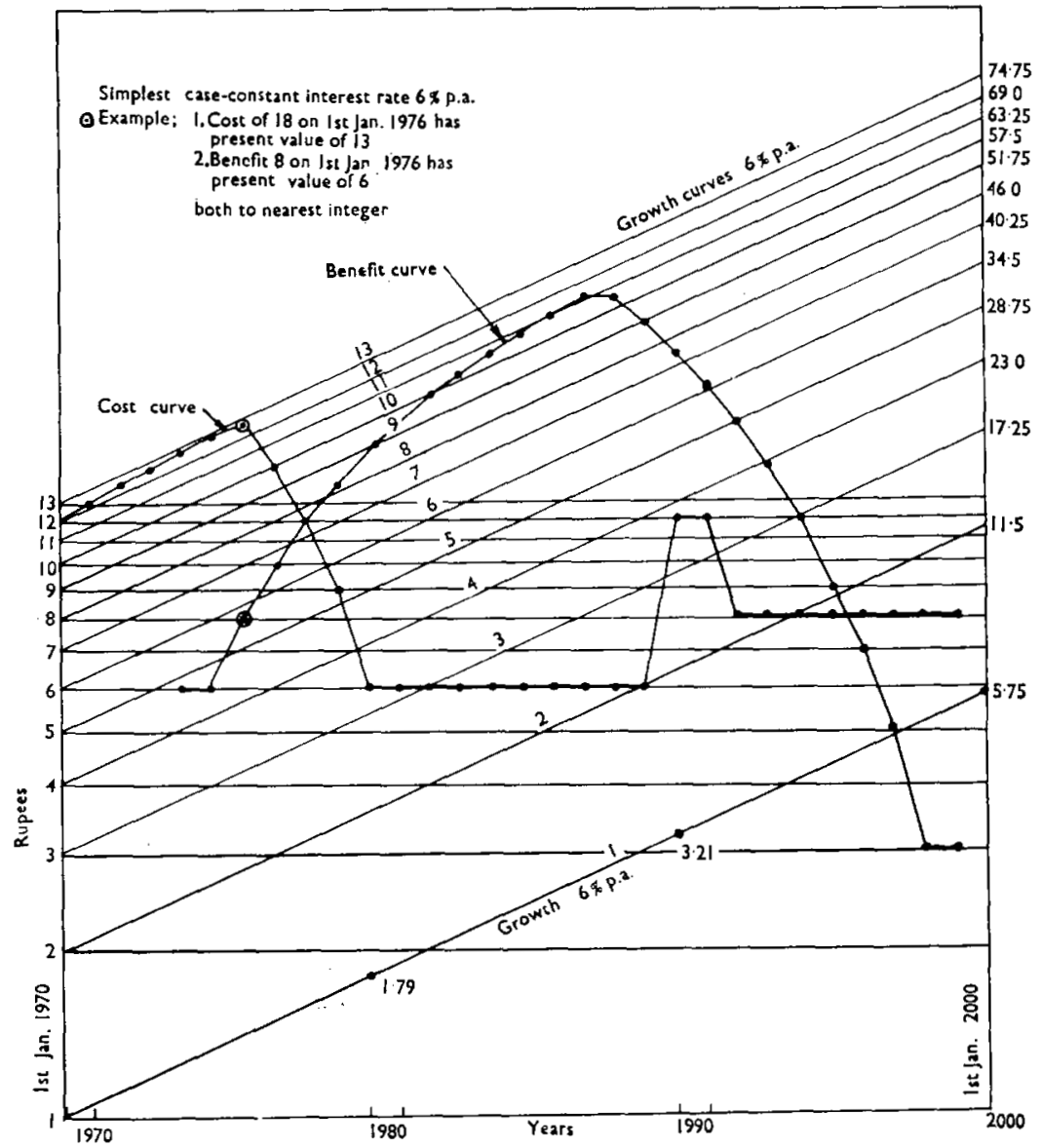

Fig. 11 
round with $(1+i)^{n}$ at year 0 and $(1+i)^{0}$ at year $n$ and plots his annual expenditures on that graph paper, then a planimeter will give the future discounted cash flows to the end of his accounting period very quickly and there would be no need to count squares. If the present value of the benefit surplus is required, the difference between discounted benefits and discounted costs is divided by $(1+i)^{n}$. If the ratio is required, no such division is necessary.

28. Second, a standard graph paper could be drawn up, say to cover the highest likely interest over a 30 year period. For lower rates of interest, the year marks could then be moved closer together so that the overall ratio of $(1+i)^{n}$ is the correct value. This will be true because the curve $y=a x(1+i)^{x}$ remains logarithmic in form no matter what the values of $a$ and $i$ and $y=a$ when $x=0$ for all values of $i$.

29. To illustrate this point, say the basic graph paper is drawn so that $30 \mathrm{~cm}$ equals 30 years and the rate of interest chosen is $10 \%$. Then $(1+i)^{n}=17 \cdot 45$.

30. If it is required to use this graph paper for a rate of interest of $71 \%$ then $(1+i)^{30}=8 \cdot 16$ and this value would be reached on the standard paper in log $8 \cdot 16 / \log 1 \cdot 1$ which is $22.02 \mathrm{~cm}$ and therefore 1 year would be represented by $7 \cdot 34 \mathrm{~mm}$.

31. Even variable rates of interest, as mentioned by the Author, could be accommodated by marking off the appropriate years to the appropriate scale.

32. This discussion is submitted by the kind permission of Mr J. P. Kriel, Secretary for Water Affairs.

\section{Mr M. Zelman, Department of Supply and Services, Ottawa}

The Author is apparently labouring under some misapprehensions regarding the objectives and uses of benefit-cost analyses, the analytical techniques and the methods of calculation. ${ }^{1-12}$

34. In very broad terms, civil engineering projects may be classified into two main groups, i.e. those in the public sector producing a widely-shared public good and those in the private sector carried out primarily for profit.

35. In the public sector, the analyst is generally concerned with the most efficient use of resources to achieve some quantity of socially desirable outputs which cannot necessarily be adequately represented by monetary values. Thus, all monetary transactions can be identified as positive or negative costs and projects can be evaluated on the basis of a benefit-cost ratio expressed as

$$
\frac{\text { time stream of stated benefits }}{\text { present value of future cash flow }}
$$

36. Since the interest rate for the present value calculation is likely to be

(a) the cost of borrowing long term funds

(b) the anticipated opportunity return on held funds or

(c) a policy determined figure by authority

the present value of future cash flows can be reasonably accurately determined for any set of assumptions using tables, calculating machines or computers if they are available. The specific decision on which of the above interest rates is to be used will always be a political decision for public sector projects, since what is being determined is essentially the relative value of services provided to fut ure generations at the expense of the present generation. Thus, the discount rate to be applied to the analysis of a highway project as an economic tool is likely to be different from that used for the conservation of an area as a national park. Under these circumstances, the use of variable interest rates on the benefit side of the equation becomes irrelevant.

37. With regard to the effect of future inflation on operation and maintenance costs, the situation is even simpler. Assuming the elementary case of a constant annual cost for operations and maintenance over the life of the project, the present value of this cost is

$$
\sum_{i=1}^{N} \frac{O}{(1+R)^{i}}
$$


where $O$ is the annual cost for operations and maintenance, $R$ is the discount rate and $N$ is the life of the project in years.

38. This can be summed very simply as a geometric series and calculated with or without the use of tables, calculating machines, etc. Now if it is assumed that an inflation rate of $r \%$ is likely to occur in the future, the expression is modified to become

$$
\sum_{i=1}^{N} \frac{O(1+r)^{t}}{(1+R)^{i}}
$$

However, this total process, simple as it is, is irrelevant by itself since the total cash flow is the critical factor to be considered against future benefits.

39. This argument may best be illustrated by two simple examples, one for the private sector and one for the public sector. Assuming that the prime motivation in the private sector is profitability, a reasonable selection criterion for projects might be the ROI, or return on investment. For any single year the factors to be considered would then include: $F$ the finance charges for interest and amortization of debt, $O$ the operation and maintenance costs, $T$ taxes of various types, $R$ the raw materials used, $P$ the production costs, $S$ the value of sales, etc.

40. The positive cash flow for any one year is then

$$
C_{t}=S_{i}-P_{i}-R_{t}-T_{i}-O_{i}-F_{i} \ldots
$$

and return on investment is the particular value of $X$ (an interest rate) for which

$$
\sum_{i=1}^{N} \frac{B_{i}}{(1+X)^{1}}=\sum_{i=1}^{N} \frac{C_{i}}{(1+X)^{1}}+\frac{\text { residual value }}{(1+X)^{N}}
$$

over the life of the project where $B$ is the investor's own contribution to the development. This procedure may be modified by special constraints such as policies on debt-equity ratios, monotonic rise of profits, etc., but essentially the method is as indicated.

41. For public sector projects the procedure is slightly different. Assuming that the objective of the project is not the making of money but the provision of a public service of some type, the benefits to be provided may either be unquantifiable, quantifiable with no monetary equivalent or have shadow prices allocated to them. As mentioned previously, the discount rate is a policy decision and the results can then be presented as a benefit-cost ratio or max. net benefit if shadow prices are used, or as a cost effectiveness statement in the other two cases. Thus, if $C_{i}$ represents the costs in year $i$, i.e. operation and maintenance + consumables + interest charges where applicable, revenues, etc., and $B_{i}$ is shadow price values of benefits in year $i$, then the benefit-cost ratio can be expressed as

$$
\frac{\sum_{i=1}^{N} B_{i} /(1+R)^{i}}{\sum_{i=1}^{N} C_{i} /(1+R)^{i}}
$$

It should be noted, however, that the discount ratios for costs and benefits are not necessarily the same and, as a matter of policy, may be deliberately different.

42. If shadow prices cannot be used, discounting techniques cannot be used and cost effectiveness becomes a more rational tool. This can be expressed as

$$
\sum_{i=1}^{N} C_{i} /(1=R)^{i}
$$

for the identified package of benefits.

43. The real problem, however, does not lie in the procedure of the analysis but in the identification of objectives for the project. Strictly speaking, the benefits of a project are those things which contribute to the achievement of the objectives of the 
client, while costs are those things which detract from his objectives. For a commercial client the objective may be as simple as 'to maximize his profit subject to specific constraints laid down by company policy'. Benefits and costs can be easily identified and any anticipated variations in the parameters can be included in the analysis without undue difficulty. Depending on the level of accuracy required and equipment available, the arithmetic can be done by a slide rule, calculating machine, with or without tables, or computer.

44. For public sector projects the clear identification of costs and benefits is much more complex and subjective. The function of analysis in this case is no longer the decision process itself, but more rationally becomes the clarification of the economic costs of achieving socio-political ends. The arithmetic is no more complex than in the commercial case and is carried out in essentially the same way.

45. In both cases, it is important to guard against a spurious precision which contributes nothing to the accuracy and reliability of the answer. While intellectually it may be fascinating to calculate the effect of future variations in interest rates which may be assumed to follow a variety of complex mathematical functions, with our imperfect knowledge of the future, it is probably reasonable to assume a constant figure with simple sensitivity tests to check the effects of possible variations.

46. Considering this 'family' of analytical techniques in the same context as any other engineering calculation a number of basic rules apply.

(a) The cost of the analysis must be justified by the value of the answer.

(b) The precision of the process must be justified by the required accuracy of the answer and knowledge about the behaviour of the parameters involved.

(c) Assumptions about an unknown future are no substitutes for sensitivity tests about the importance of specific parameters.

47. This then suggests a number of principles to be followed in this type of analysis (not necessarily in order).

(a) Determine the use to be made of the answer and the accuracy required.

(b) Define the objectives of the project in consultation with the client and define the nature of benefits and costs.

(c) Use the simplest possible method of analysis to give an answer of the accuracy required.

(d) Make only such assumptions as are absolutely necessary, identify them as assumptions and check the answer for sensitivity to variations in the assumptions.

Mr N. S. Collie, G. Maunsell \& Partners

The Paper presents an interesting method for discounting irregular benefit or cost streams. Simple formulae are available, however, which will discount any benefit (or cost) stream which can be approximated to a series of straight lines.

49. Most benefit streams can be assumed to be of this form; the annual benefits may be calculated for two or three future years and a linear growth of benefits assumed between these years. The benefit curve may contain discontinuities when further stages are added to schemes, as illustrated in Fig. 12.

50. The benefit (or cost) stream is divided into triangular and rectangular areas. These areas are discounted to the start year by using the following formulae, and the total discounted benefit (or cost) is the summation of the various discounted areas. The most general forms of the problem as described in $\S 3$ can all be solved quickly and easily. In the case where it is assumed that the interest rate $i$ varies, the relevant blocks are discounted at interest rate $i_{2}$ to the first year of that interest rate (say year $\left.Y_{2}\right)$ and then this sum is discounted to the start year $\left(Y_{B}\right)$ at the current interest rate $i_{1}$ by the usual formula

$$
\left.\begin{array}{c}
\text { benefits discounted to } \\
\text { start year }\left(Y_{B}\right)
\end{array}\right\}=\frac{1}{\left(1+i_{1}\right)^{n}} \times\left\{\begin{array}{c}
\text { benefits discounted at } \\
\text { rate } i_{2} \text { to year } Y_{2}
\end{array}\right\}
$$


where $n=Y_{2}-Y_{B}$ (=number of years from start year to first year that interest rate is $i_{2}$ ).

51. It is convenient to assume, although not essential, that the annual benefits (or costs) can be represented by single payment at the midpoint of the year to be discounted to the midpoint of the start year. Care must be taken to define the time of the beginning and end of the benefit (or cost) stream.

52. Let the annual benefits for year $Y_{1}$ be $B_{1}$ occurring at the midpoint of the year, rising linearly to a value $\left(B_{1}+B_{2}\right)$ for year $Y_{1}+N$ (i.e. the total time period is $N+1$ years). Thus the benefits in any year $Y_{1}+y$ consist of a constant component $B_{1}$, plus an increasing component equal to $\left(y / N . B_{2}\right)$, see Fig. 13.

53. In case I, uniform (rectangular) benefits, the uniform annual benefit component $B_{1}$ is discounted to the midpoint of year $Y_{1}$ giving

Discounted rectangular component for year $Y_{1}=B_{1} .1$

Discounted rectangular component for year $Y_{1}+1=B_{1} \cdot \frac{1}{(1+i)}$

Discounted rectangular component for year $Y_{1}+2=B_{1} \cdot \frac{1}{(1+i)^{2}}$

Discounted rectangular component for year $Y_{1}+N=B_{1} \cdot \frac{1}{(1+i)^{N}}$

Let $u=1 /(1+i)$, and summing all these benefits, total benefit for a uniform annual benefit $B_{1}$ during $N \times 1$ years discounted to year $Y_{1}$

$$
\begin{aligned}
& =B_{1} \cdot\left[1+u+u^{2}+\ldots u^{N}\right] \\
& =B_{1} \cdot\left[\frac{1-u^{(N+1)}}{(1-u)}\right]
\end{aligned}
$$

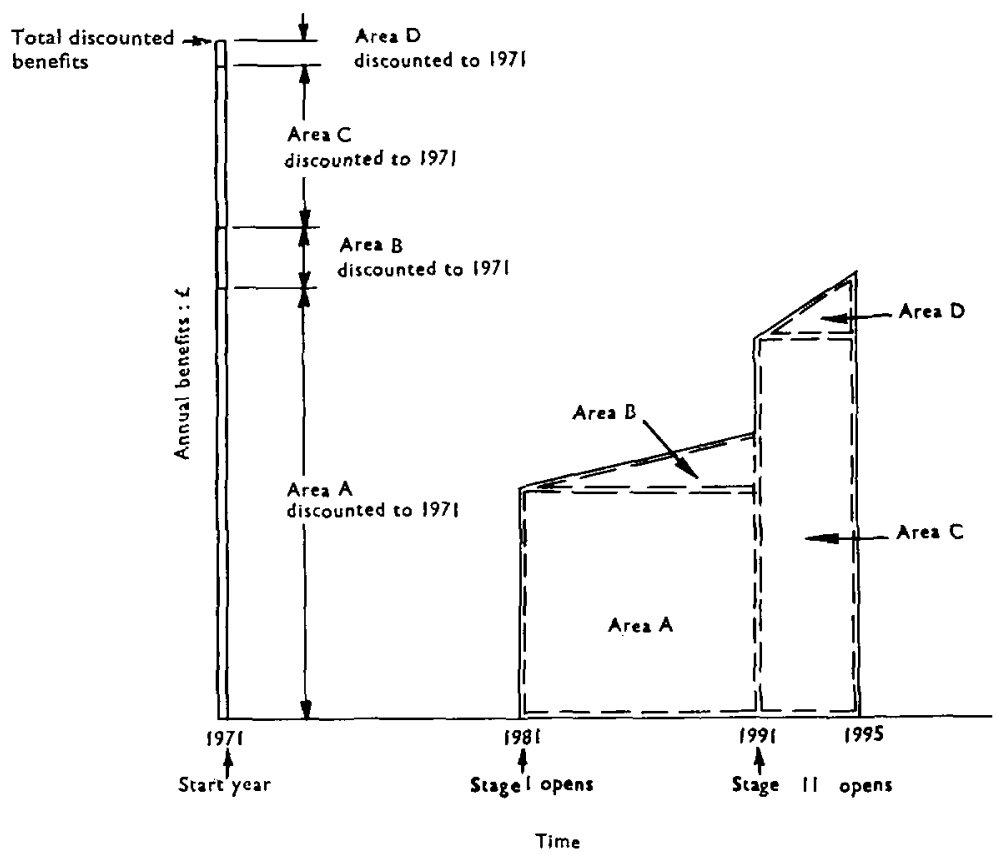

Fig. 12. Method of subdivision of benefit stream 
54. This sum can be discounted back to the start year, $K$ years earlier, by the usual method of multiplying by $1 /(1+i)^{K}$. Total uniform benefits $\left(D_{1}\right)$ discounted to start year are

$$
u^{K} \cdot B_{1} \cdot\left[\frac{1-u^{(N+1)}}{(1+u)}\right]
$$

55. Case II represents the linearly increasing (triangular) benefits. The increasing annual benefit component $\left(y / N, B_{2}\right)$ is discounted to the midpoint of $Y_{1}$ giving

Discounted triangular component for year $Y_{1}=0$

Discounted triangular component for year $Y_{1}+1=B_{2} \cdot \frac{1}{N} \cdot \frac{1}{(1+i)}$

Discounted triangular component for year $Y_{1}+2=B_{2} \cdot \frac{2}{N} \cdot \frac{1}{(1+i)^{2}}$

Discounted triangular component for year $Y_{1}+N=B_{2} \cdot \frac{1}{(1+i)^{N}}$

56. Letting $u=1 /(1+i)$, and summing all these benefits, the total benefit for a linearly increasing benefit from zero in year $Y_{1}$ to value $B_{2}$ in year $\left(Y_{1}+N\right)$ discounted to year $Y_{1}=B_{2} / N .\left[0+u+2 u^{2}+\ldots N u^{N}\right]$. The sum of this series is developed in $\$ \$ 57-59$ giving

$\left.\begin{array}{l}\text { Total linearly increasing benefits }\left(D_{2}\right) \\ \text { discounted to the start year }\end{array}\right\}=u^{K+1} \frac{B_{2}}{N} \cdot\left[\frac{1+N u^{N+1}-(N+1) u^{N}}{(1-u)^{2}}\right]$

57. Let the sum of linearly increasing benefits equal $S$. Then

$$
S=\frac{B_{2}}{N} \cdot\left[0+u+2 u^{2}+3 u^{3}+\ldots N u^{N}\right]
$$

Dividing both sides by $u$

$$
\frac{S}{u}=\frac{B_{3}}{N} \cdot\left[1+2 u+3 u^{2}+\ldots N u^{N-1}\right]
$$

58. Integrating both sides with respect to $u$

$$
\begin{aligned}
S \cdot \int \frac{1}{u} \mathrm{~d} u & =\frac{B_{2}}{N} \cdot\left[u+\frac{2 u^{2}}{2}+\frac{3 u^{3}}{3}+\ldots \frac{N u^{N}}{N}\right]+\text { constant } \\
& =\frac{B_{2}}{N} \cdot\left[u+u^{2}+u^{3}+\ldots u^{N}\right]+\text { constant } \\
& =\frac{B_{2}}{N} \frac{u\left(1-u^{N}\right)}{(1-u)}+\text { constant }
\end{aligned}
$$

59. Differentiating both sides with respect to $u$

$$
\begin{gathered}
\frac{S}{u}=\frac{B_{2}}{N} \cdot\left[\frac{(1-u) \cdot\left[1-(N+1) u^{N}\right]+u\left(1-u^{N}\right)}{(1+u)^{2}}\right] \\
=\frac{B_{2}}{N} \cdot\left[\frac{\left.1+N u^{N+1}-(N+1) u^{N}\right]}{(1-u)^{2}}\right]
\end{gathered}
$$

Therefore, sum of the series:

$$
S=u \cdot \frac{B_{2}}{N} \cdot\left[\frac{1+N u^{N+1}-(N+1) u^{N}}{(1-u)^{2}}\right]
$$

60. The analysis can also be extended to include the case when the project life is indeterminate by obtaining the values in the limit as $N$ approaches infinity. If the benefit (or cost) stream can be assumed to be uniform continuing at the same annual 
value beyond the foreseeable future then the total uniform benefits discounted to start year, $K$ years before the first benefit

$$
\begin{aligned}
& =\lim _{N \rightarrow \infty}\left\{u^{K} \cdot B_{1} \cdot\left[\frac{1-u^{(N+1)}}{1-u}\right]\right\} \\
& =\frac{u^{K} B_{1}}{(1-u)}
\end{aligned}
$$

61. Similarly, if the unlikely assumption is made that the benefits continue to increase linearly beyond the foreseeable future and provided the interest rate is positive then equation (2) converges as $N$ approaches infinity.

62. Total linearly increasing benefits discounted to start year, $K$ years before the start of the benefit stream

$$
=\lim _{N \rightarrow \infty}\left\{u^{K+1} \cdot G \cdot\left[\frac{1+N u^{N+1}-(N+1) u^{N}}{(1-u)^{2}}\right]\right\}
$$

where $G=B_{2} / N=$ gradient of benefit curve (constant).

63. Thus equation (4) becomes

$$
\begin{aligned}
& =\frac{u^{K+1} \cdot G}{(1-u)^{2}} \cdot \lim _{N \rightarrow \infty}\left\{1+N u^{N+1}-(N+1) u^{N}\right\} \\
& =\frac{u^{K+1} \cdot G}{(1-u)^{2}}
\end{aligned}
$$

provided $u$ is less than unity, i.e. that the interest rate $i$ is greater than zero.

64. The total benefit stream shown in Fig. 13, discounted to the start year, is the sum of $D_{1}$ plus $D_{2}$. Equations (1) and (2) thus provide a simple means to discount any benefit stream by approximating to triangles and rectangles. A linearly decreasing benefit stream is discounted by computing the value for the enclosing rectangle using equation (1) and subtracting the value for a linearly increasing triangle using equation (2).

65. The two equations have been programmed using a Hewlett Packard 9810A

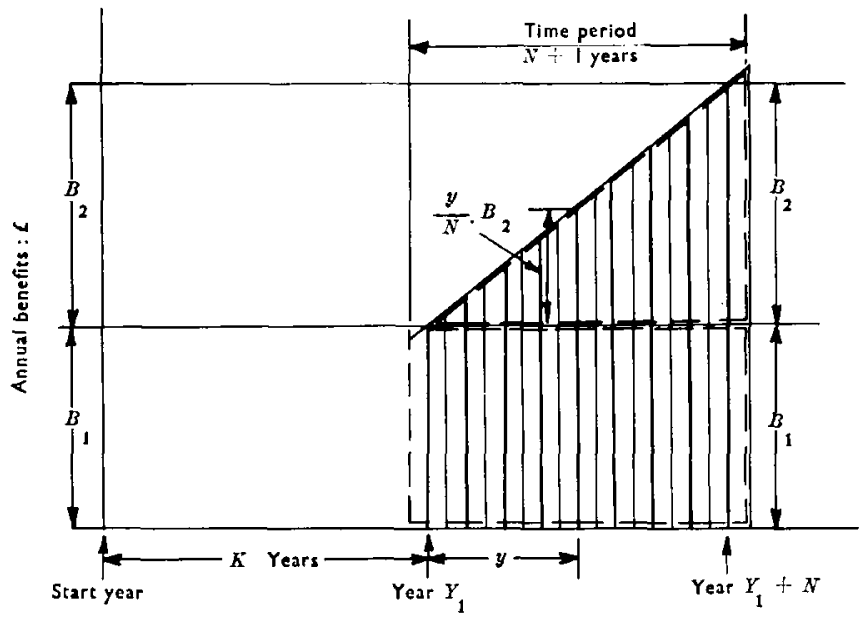

Fig. 13. Linear increasing benefit stream 
programmable calculator to provide immediate answers based on the following parameters:

$\begin{array}{cl}K & \text { number of years to start of benefit stream } \\ i & \text { interest rate } \\ (N+1) & \text { time period of benefit stream } \\ \text { and } B_{1} & \text { (rectangular case) uniform annual benefit } \\ \text { or } B_{2} & \text { (triangular case) final value of triangular benefit stream. }\end{array}$

66. However, the values in these formulae may also be easily computed manually for different streams, interest rates, or project lives especially with the aid of standard discount tables or logarithms. It is considered that this method will be significantly quicker than the graphical method advocated by the Author.

\section{Mr M. R. Broome, Department of the Environment}

The idea of pre-printed curves showing the future values of one monetary unit today at various rates of interest, is an excellent one. When this is coupled with a graphical presentation of costs and benefits so that the cost-benefit ratio can be arrived at by counting squares, the resulting operation becomes obvious even to the most nonnumerate of decision-takers. An additional advantage from the use of this method is that it automatically compares the whole costs of a project with the whole benefits instead of the sometimes misleading ratio of annual figures. It is often argued that the rate of discount to be used cannot be chosen with any accuracy for long term projects. Whatever the merits of this argument, the Author's method provides a quick and accurate tool for a sensitivity analysis of the chosen value.

68. The difficult part of cost-benefit analysis, however, remains the actual assessments of the value and timing of the costs and the benefits. Here, despite the promise held out by the title, we are no further forward. The essence of any cost-benefit analysis is its inclusion of all the costs and all the benefits, both financial and social. The potential social benefits from investments in power and water resources in West Pakistan must be immense and it would be interesting to know the unit values put on them by the Development Authority when considering the relative merits of alternative proposals.

\section{Mr J. P. Hanlon, The University of Birmingham}

In my view the technique described in this Paper is a less convenient means of evaluating the economic merit of an investment than the conventional arithmetic methods. Criteria based on the calculation of the net present value (NPV) of a proposed investment can, in principle, take account of all possible variations in interest rates, operating and maintenance costs and annual benefits. But it is not clear which interestrate variations should be examined. The considerations involved are much more complex than is implied in the Paper.

70. The Author introduces his technique by describing the annual capital charge (sinking fund) method of project appraisal. In this method, the initial capital cost of $£ P$ is expressed as the equivalent of a constant amount payable at the end of each of $n$ years (where $n$ is the expected useful life of the project). In other words, the capital expenditure is treated as an annuity over the life of the project. In the Author's notation, this annuity is $D=P i /(1+i)^{n}-1$, the amount which would just suffice to recover the initial cost together with interest (at rate $i$ ) on the outstanding balance from year to year. It is thus the measure of the minimum annual net benefit required to justify the initial expenditure of $£ P$, on the assumption that this minimum net benefit is the same in each year. Where this amount is less than the expected net benefit, the difference between annual benefits, $B$, and annual operating and maintenance costs, $a$, the project can be deemed worth while on economic grounds. (The benefitcost ratio criterion given in the Paper is incorrect.)

71. The Author then points out that the annual net benefit cannot always be 
assumed to be constant. If the net benefit expected from the project varies over time, there is no advantage in using the annual capital charge method of appraisal. Rather, a more appropriate investment criterion would be one based on the NPV of the project. Employing the same notation as in the Paper and using subscripts to denote periods in the life of the project from the present (period ${ }_{0}$ ) to termination $\left(\right.$ period $_{1}$ )

$$
\mathrm{NPV}=-P+B_{0}-a_{0}+\left(B_{1}-a_{1}\right) /(1+i)+\left(B_{2}-a_{2}\right) /(1+i)^{2}+\ldots+\left(B_{\mathrm{n}}-a_{\mathrm{n}}\right) /(1+i)^{n}
$$

The mechanics of NPV calculations are set out clearly in a number of textbooks ${ }^{13,14}$ and all that need be noted here is that a positive NPV indicates that the project can be expected to be worth while. In this procedure, it need not be assumed that $B, a$ and $i$ are constant from year to year. But, in practice, a single predetermined value of $i$ is used as the discount rate.

72. Turning to the question of allowing for variations in interest rates, consider first the significance of the rate of interest in investment appraisal for a firm in the private sector of an economy. A firm will not consider expenditure of the sum $f P$ profitable unless the net return from the project is greater than the return obtainable by investing $f P$ in the best alternative. This may be to place the money on loan, the return on which is the interest earned. In other words, the opportunity cost to the firm of devoting $£ P$ to the project is indicated by the market rate of interest earned by investment of this sum elsewhere. It is true that the appropriate interest rate can vary over time and, indeed, it will be influenced by the general economic climate and by changes in the monetary policy pursued by the government. But it should also be recognized that the market interest rate varies directly with the length of the period for which the loan is made: in general, the variation within the term structure of interest rates is greater than the variation over time in one particular rate (and, in some cases, the rate of interest earned/charged is fixed in advance for the period of the loan).

73. Considerations such as these make the analysis of expected variations in interest rates a complex exercise. To reflect variable interest rates in assessments based on NPV, the calculation may be modified to

$$
\mathrm{NPV}=-P+B_{0}-a_{0}+\frac{\left(B_{1}-a_{1}\right)}{\left(1+i_{1}\right)}+\frac{\left(B_{2}-a_{2}\right)}{\left(1+i_{1}\right)\left(1+i_{2}\right)}+\frac{\left(B_{\mathrm{n}}-a_{\mathrm{n}}\right)}{\left(1+i_{1}\right)\left(1+i_{2}\right)} \ldots\left(1+i_{\mathrm{n}}\right)
$$

where $i_{1}, i_{2}, \ldots, i_{\mathrm{n}}$ are the appropriate rates of interest reflecting opportunity cost in each period during the life of the project.

74. The usefulness of this refinement is likely to depend on the purpose of the appraisal. Where the objective is to determine whether a project, considered on its own, is likely to yield sufficient net benefits to justify the initial capital cost, there will be formidable difficulties in forecasting the changes in interest rates over the whole life of the project. Where the purpose of the appraisal is to select between two or more proposed projects which can be regarded as mutually exclusive alternatives, the need to consider temporal variations in interest rates is less likely to arise: unless the time-profiles of benefits and costs are significantly different between one alternative and another, variations over time in interest rates will affect each of the proposals in much the same way, in which case any allowance for these variations will have little influence on the comparisons made. On the other hand, where the decision concerns the timing of the commencement of the project, expectations of the future course of interest rates will clearly be important.

75. In the assessment of public investment projects, there is the further consideration that the interest rate used to discount future benefits and costs implies a certain "social rate of time preference"15 and from this point of view the discount rate can be regarded as a constant factor. In 1967, the British Government laid down that, in the assessment of public investment projects, the rate of discount was to be at $8 \%$ per annum. ${ }^{16}$ Subsequently, this test rate of discount was raised to $10 \%$. 
76. Thus, it is argued that the conventional arithmetic methods of project evaluation are more convenient than, and of as general application as, the Author's graphical method. It is agreed that standardized prints of the diagrams presented can be useful to the lay investor, but it is submitted that the assessment of large projects should be subject to more precise criteria, particularly where the investment decision involves a choice between two or more alternatives.

\section{Mr Khalid Asmi}

If it is accepted that my method is easy to understand, easily workable, mathematically valid and sufficiently accurate, I would venture to say that it should find its place among existing methods in vogue.

78. From the criticism received and from my personal experience $I$ have found that the method described in Technical Note 51 has been able to eliminate many fallacies and misconceptions and I hope to make further clarifications. It is unfortunate that a subject as important as the present one has been misunderstood by many engineers, for example, many people confuse financial returns with the economic benefits of a project. Similarly, it is not the first time that I have noted that many people believe that the sinking fund deposit $D$ is the amount which would recover the initial cost together with interest on the outstanding balance in $n$ years $(\S 70)$. The form of the equation $D=P i /(1+i)^{n}-1$ shows that the higher the value of interest $i$, the lower will be the value of $D$. Thus if we were to accept the contention of $\mathbf{M r}$ Hanlon, this would mean that the higher the rate of interest, the less would have to be paid annually to recover the capital plus interest. This would be ridiculous.

79. Some critics have said that there are several mathematical methods available for benefit-cost evaluation which it has been claimed are more convenient to use. Other critics have agreed that my proposed method is simpler and quicker but they have pointed out that the subject of actual assessment of economic benefits has not been dealt with. It has been contested that my method would be useful mainly for the lay investor.

80. While it is debatable which method seems simpler and quicker to the individual, I can say from personal experience that the method I have described has generally created better understanding of the subject among the engineers who have been following other mathematical methods and have been harbouring several misconceptions about the subject.

81. I would submit that I described only the actual method of benefit-cost evaluation, starting from the assumption that the benefits and costs have already been assessed. This was necessary for conciseness.

82. I agree that I have deliberately made my method so simple as to be equally useful to the layman. But what is a layman? He is not an illiterate person. From the investment point of view, those who are highly educated in their respective fields are laymen as long as they do not have a clear understanding of the subject of economic evaluation. The people who usually take decisions regarding investment policies may be eminent engineers with little understanding of economics or eminent administrators with little knowledge of engineering and economics.

83. Such decision-makers may have misconceptions regarding the subject of economic evaluations, e.g. confusion regarding financial returns and economic benefits. One comes across such ideas that if $f 100$ are invested in a project with a financial return of $£ 10$ per annum, the project pays back the investment in ten years. This would be true only in an economy where the interest rate is zero; this does not exist anywhere. The present worth of the financial return is relative to the time of payment/receipt. These are elementary ideas and yet they are misunderstood. 
84. The process of benefit-cost evaluation can be distorted by juggling the mathematics in such a way as to misguide the decision-maker. Consider an irrigation/ power project with the following data:
annual costs (direct)
Rs 10 million*
net annual increase in crop produce
Rs 50 million
net annual income from power sales
Rs 9 million

Benefit-cost ratio can be calculated in different ways with equal mathematical validity:

(a) benefit-cost ratio $=(50+9) / 10=5 \cdot 9$

(b) since Rs 9 million is the net income from the project, net annual cost would be Rs $(10-9)$ million.

Therefore benefit-cost ratio $=50 /(10-9)=50$

85. Karachi Irrigation Project in Pakistan is proposed to be partially financed by sale of Government land in the project area. The increase in the price of land can be added to the project benefits or it can be deducted from the cost of the project, thus there can be two values of benefit-cost ratios. Therefore it can be said that the projects should be judged by the surplus of benefits over costs rather than benefit -cost ratios.

86. In reply to Mr Bannerman, I considered the possibility of using semi-log paper but I discarded the idea because in a diagram plotted on a natural scale, even by visual inspection, one can judge the value of costs/benefits. However, some may find $\mathrm{Mr}$ Bannerman's suggestions useful.

87. Mr Littleworth has rightly pointed out that calculation of water tariff is a problem very similar to the benefit-cost evaluation. For water supply projects, as well as for power projects, the tariffs for water or power can be calculated by my method by equating benefits to costs, i.e. by making benefit-cost ratio $=1$. I think that there are some mathematical errors in $\$ \$ 25$ and 26.

88. I considered the possibility of making my graph paper in the inverted direction, as suggested by Mr Littleworth, but discarded the idea on the grounds that the use of a planimeter may not be convenient for many people. The counting of squares does not take much time, has little chance of error and therefore creates a sense of confidence in the user of this method.

89. I agree with $\mathbf{M r}$ Zelman that the actual assessment of benefits is much more important than the method of evaluating the benefit-cost ratio. However, the assessment of benefits of projects does not require any arithmetical method. To forecast all economic benefits accruing from a project, one needs a broad vision and a clarity of thought regarding the objectives and the effects of the project.

90. Mr Zelman seems to have confused the financial return with the economic benefits. To avoid this confusion, let me state that the financial analysis and the economic analysis are two entirely different things. Consider the case of the irrigation project as in $\S 84$. The financial return from this project would be based on the water tariff charged from the cultivators, whereas the economic benefits would be based on a certain percentage of the increase in the crop produce in the area under irrigation. The objection regarding variable interest rate has already been dealt with in $\S 12$. Changing interest rate has important practical applications as in the example of $\S 75$ where interest rate was increased from $8 \%$ to $10 \%$.

91. Mr Collie has defended the existing mathematical methods which can also be used by computers. However, I feel that our entry into the computer room should not be followed by a closed door policy. I would ask $\mathrm{Mr}$ Collie to consider that computers are not available everywhere and that my method may be found quite useful because no reference tables etc. are needed and the analysis can be performed $a b$ initio.

* $f 1$ sterling $=32$ rupees (West Pakistan). 
92. Regarding the question raised by Mr Broome of assessment of actual benefits and costs of a project, definitions in $\$ \$ 93-104$ would be relevant. ${ }^{17}$

93. Costs and benefits will be divided into primary and secondary types. Primary costs are further divided into 'direct' and 'associated' costs.

94. The direct costs of a project are the value of the goods and services used in the establishment, maintenance and operation of the project throughout its useful life; associated costs cover the preparation for use or sale of the goods or services produced by the project. For example, in an irrigation project the direct costs are those required for placing the water at the disposal of the farmer, including those for the operation and maintenance of the irrigation works; the associated costs are those incurred by the farmer, excluding the cost of the water, in order to work the irrigated lands and produce crops.

95. The value of the goods and services obtained from the use of resources represented by the direct costs and the associated costs are the primary benefits. In the example of the irrigation project, the primary benefits are the value of the wheat produced by the farmer. These provide the basis for calculating net benefits attributable to the project, which will be discussed later.

96. The secondary costs are the value of the goods and services used as a consequence of the project, excluding direct and associated costs. They include subsequent manufacturing costs of the immediate goods or services of the project and all costs over and above the 'direct' and 'associated' costs deriving from or induced by the project. For example, in the irrigation project the costs of transport, milling of the wheat, baking and distribution would be secondary costs.

97. The secondary benefits are those values which are added over and above those of the project's immediate goods and services as a result of activities which it initiates or induces. Using the same example, the difference between the value of the bread and that of the wheat which it contains would be a secondary benefit.

98. In normal cases, the relative merits of a certain number of projects may be determined satisfactorily be measuring only the costs and benefits of the projects themselves, that is, excluding the secondary stage. In cases where the associated and secondary costs have special importance, or where they vary greatly between projects under comparison, it may be desirable to compare the sum of the secondary and associated costs of the projects with the gross benefits obtained.

99. In pricing, the possibility is acknowledged, in principle, of applying an opportunity cost of zero if, in the absence of the project, there would have been no alternative use for the resources. There would usually be other uses. For normal cases, it is accepted that market prices may be used. For pricing of labour during periods of unemployment it will be necessary to adjust the market price.

100. Among all the primary and secondary benefits, only those 'attributable to the project' are singled out. The project must be credited with the difference between the total primary benefits, as defined, and the associated costs. In the example of the irrigation project for the production of wheat, the primary benefit attributable to the project is the market value of the wheat, less the farmer's costs but excluding from these the payments made for the use of the water which is the immediate benefit of the project.

101. Secondary benefits cannot be attributed to a project unless it can be shown that there is an increase in them over what would have been received without the project; all values which would in any case have added to production in similar activities connected with the project should be subtracted from the total.

102. If an annual deposit $D$ is placed in a bank at the annual compound interest rate $i$ and after $n$ years the total deposit plus interest becomes equal to $P$, then $D$ is defined as 'sinking fund deposit' (SFD) for the investment $P$ for $n$ years at the interest rate $i$. It is obvious that for the given interest rate, an annual payment of $D$ for $n$ 
years is in economical terms equal to a single future payment $P$ after $n$ years.

$$
D=P\left[\frac{i}{(1+i)^{n}-1}\right]
$$

The term $i /(1+i)^{n}-1$ is called the 'sinking fund factor'.

103. In the equation in $\S 102$, an annual payment $D$ for $n$ years is economically equivalent to a single future payment $P$ after $n$ years. To find the annual payment $A$ which paid over a period of $n$ years is economically equivalent to the present payment $P$, the following equation is used.

$$
A=\frac{P\left[i(1+i)^{\mathrm{n}}\right]}{(1+i)^{\mathrm{n}}-i}
$$

The term $i(1+i)^{n} /(1+i)^{n}-1$ is called the 'capital recovery factor' (CRF). It may be noted that

$$
\begin{aligned}
A & =D+P i \\
& =P\left[\frac{i}{(1+i)^{n}-1}\right]+P i \\
& =P\left[\frac{i(1+i)^{n}}{(1+i)^{n}-1}\right]
\end{aligned}
$$

Therefore $\mathrm{CRF}=$ sinking fund factor $+i$.

104. The reciprocal value of CRF is known as 'present worth factor' (PWF). If an annual payment $R$ is made for $n$ years and it is required to find its equivalent initial investment $P$, then $P=R \times \mathrm{PWF}=R / \mathrm{CRF}$.

105. In West Pakistan, the economic benefits of irrigation projects have been calculated on the basis of increase in the crop produce. For example, an area previously cultivated mainly by rainfall is brought under irrigation by constructing a reservoir and irrigation channels. The result is an increase in the crop produce of, say, Rs 10 million. To achieve this benefit, apart from the project cost, expenditure has been incurred by the farmers on land management, seeds, fertilizers, agricultural machinery and so on. The usual practice in Pakistan is to assume that at least $50 \%$ of the economic benefit is attributable to the projects; in this case the economic benefits from the project would be Rs 5 million.

106. Based on the practice just described, the usual figure of benefits/costs is between $2 \cdot 5 / 1$ to $5 / 1$ in West Pakistan but there are other costs benefits such as usage of canal water as drinking water in far flung villages.

107. For power projects and for municipal water supplies, the benefit-cost ratio is not relevant if the supplier has the absolute choice to fix the prices. However, my proposed method can be used to calculate water and power tariffs based on a certain rate of interest. From an economics point of view, the power tariff should vary from season to season, depending on supply and demand.

108. Mr Hanlon stated that the sinking fund deposit $D$ is the amount which would just suffice to recover the initial cost, together with interest on the outstanding balance in $n$ years. Thus he infers that my definition of benefit-cost ratio is incorrect.

109. As I stated in $\$ 78$ the definition of the SFD given by Mr Hanlon is not correct. I have defined terms of economics in $\$ 102$.

110. The sinking fund deposit $D=P i /(1+i)^{n}-1$ and the higher the value of $i$, the lower will be the value of $D$. Thus if Mr Hanlon's statement is accepted, the higher the rate of interest, the lesser the amount to be paid. He has obviously confused the sinking fund factor, $i /(1+i)^{n}-1$ with the capital recovery factor, $(1+i)^{n} /(1+i)^{n}-1$.

\section{References}

1. Anthony R. N. Planning and control systems - a framework for analysis. Harvard University Press, 1965. 
2. Dorfman R. Measuring benefits of government investment. Brookings Institution, Washington, DC, 1965.

3. HгтCH C. J. and McKeAN R. N. Economics of defense in the nuclear age. Harvard University Press, Cambridge, Mass., 1960.

4. Marglin S. A. Public investment criteria. Allen \& Unwin, London, 1967.

5. MCKEAN R. N. Efficiency in government through systems analysis: with emphasis on water resources development. John Wiley \& Sons, New York, 1958.

6. Novick D. (Ed.) Program budgeting. Harvard University Press, 1965.

7. Special Conference issue on decision-making. Operational Research Quarterly. 1968, 19.

8. Prest A. R. and Turvey R. Cost-benefit analysis: a survey. Economic Journal, 1965, 75.

9. Planning-programming-budgeting, Symposium. Public Administration Review, 1966, 26, 243-310.

10. SAmUelson P. and ScotT A. Economics, an introductory analysis. Canadian edition, McGraw-Hill Co.

11. Sewell W. R. D. et al. Guide to cost-benefit analysis. Queen's Printer, Ottawa, Canada, 1965.

12. US Senate Subcommittee on National Security and International OperaTIONS. Planning-programming-budgeting, official documents; Planning-programming-budgeting, selected comments; Planning-programming-budgeting, initial memorandum, 1967.

13. MERRETT A. J. and SYKES A. The finance and analysis of capital projects, Longmans, London, 1963 and Capital budgeting and company finance, Longmans, London, 1966.

14. INSTITUTION OF CIVIL ENGINEERs. An introduction to engineering economics, ICE, London, 1969.

15. Mishan E. J. Cost-benefit analysis. An informal introduction, Allen \& Unwin, London, 1971.

16. WhITE PAPER. Nationalized Industries. Review of economic and financial objectives, Cmnd 3437, HMSO, London, 1967, 5, § 10.

17. RIVER BASIN COMMITTEE. Proposed practices for economic analysis of river basin projects. Federal Inter Agency, River Basin Committee, Washington, DC, 1950. 